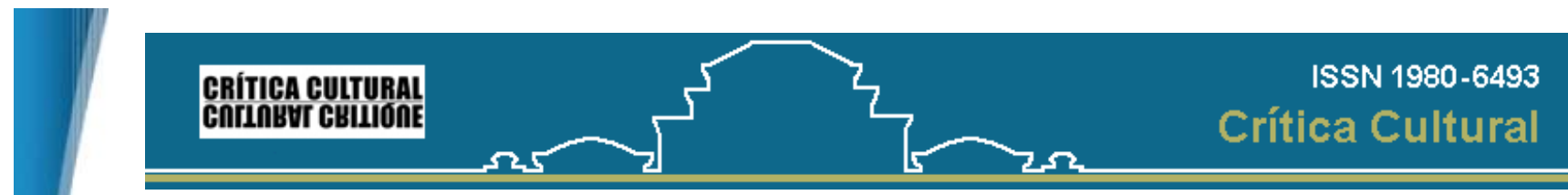

Crítica Cultural, volume 3, número 2, jul./dez. 2008

\title{
"CUANDO LAS PALABRAS (Y EL EXCESO) MANDAN" SOBRE DENZIL ROMERO
}

\author{
Mónica Marimone *
}

Resumo: 0 venezuelano Denzil Romero reescreve a História a partir da Literatura, situado na irreverência. Este artigo desenvolve algumas idéias sobre seus romances La esposa del Dr. Thorne (1988) e La Carujada (1990), sobre vida e obra da amante de Simón Bolívar e de Pedro Carujo, um dos que atentaram contra a vida de Bolívar, respectivamente. Da consideração dos eixos EDUCAÇÃO e JUSTIÇA, reconstrói um arquivo (imaginário) através do qual Romero investe nos debates entre pensadores franceses da época revolucionária, algumas fontes primárias dos escritos do século XIX latino-americano, especialmente os de S. Bolívar.

Palavras-chave: literatura, história, revolução, erotismo, Romero

\section{1.}

Algunos filósofos definen el exceso como lo que está fuera de la razón.[1] El mandato de Rousseau, “Buscad en todo la medianía" (Emilio, p. 325), o la ley de los contrapesos de Montesquieu ubican en dicha concepción revelando la necesidad de control de cualquier exceso desde la sujeción a los límites impuestos ya por variables de orden como el pudor, ya por reglas de ordenación como la norma. La razón, que impone la norma (el mundo del "deber ser" de los juristas), se ve deshecha por el exceso en cuanto transgresión de prohibiciones instauradoras de opuestos -vicio / virtud, moral / inmoral / legal/ ilegal. La reescritura de la memoria revolucionaria desde una transgresión que es puro regodeo en el exceso ha sido el motor de la alegría festiva y la moral del fracaso que impregnan la narrativa del venezolano Denzil Romero (1938-1999), un novelista que jugó a ser historiador (y la palabra juego es aquí pertinente) lanzado a controvertir, pero también a interrogar y sustraer de inercias interpretativas que contribuyeran a frustraciones políticas de algún modo expresadas en el grado cero de nuestra historia continental. Su manera de reescribir la Historia emplazado en la irreverencia pone en crisis ciertas utopías de la moderna razón occidental. Así por ejemplo, su obsesión con artefactos como "educación" o "justicia", si posibilita una revisión de las fuentes que constituyeran un fundamento para nuestros grandes inventores de naciones (por eso Rousseau y Montesquieu en mi apertura), a su vez propicia la reflexión sobre procesos actuales de los países latinoamericanos. Abrir zonas oscuras del archivo, llenar vacíos, apelar al error, indagar la contradicción, desautorizar, desvanecer lo que se ha grabado y reescribirlo obscenamente, narrar el deseo en el centro del poder, resucitar a los traidores y transformarlos en héroes, convertir a los héroes en traidores... Son los sentidos contrarios, las "verdades" a medias o lo que está en proceso. Es el rostro doble de Jano en novelas osadas de fines del s. XX donde se quiebra la concepción heroica de la historia de una nación entendida como exaltación patriótica y ocultamiento de los intereses privados de los héroes, unos intereses que asumen aquí significación pública y ocupan todo el espacio textual. Es decir, se quiebra la moral de la biografía inherente a la escritura del panteón, una moral tras la que resuena la teoría del "grande hombre" (en su caso son mujeres, traidores, condenados).Y son novelas inscriptas en una familia donde Yo el Supremo de A. Roa Bastos es tutelar. Pues cuando se trata de indagar el poder basándose en saberes, discursos, textos preexistentes y en "reales" localizados de la época en que empezaba a imaginarse, a registrarse simbólicamente la idea de nación según el modelo francés adaptado es difícil alejarse de la estela de dicha novela, suerte de "animal mitológico", un faro para muchos narradores preocupados por el principio de nuestra historia, entre ellos Romero.

La esposa del Dr. Thorne (1988)[2] y La carujada (1990)[3] constituyen la saga (el uso es de Romero) que asedia el "culto a Bolívar". La primera es una novela erótica sobre vida y obra de Manuela Sáenz, la eterna amante de Simón Bolívar; la segunda, sobre vida y obra de Pedro Carujo, un implicado en el atentado "septembrino" contra Bolívar. Ambas instalan en las opciones temáticas y discursivas señaladas: son reescrituras de un panteón nacional aunque en sentido contrario al que Renan sugiriera y muchos historiadores propusieran ("Un pasado heroico, grandes hombres, gloria... es el capital social sobre el que se asienta una idea nacional"). Y se articulan sobre una combinatoria de escritura exacerbada y de elecciones referenciales que, siendo verificables, por gestos y circunstancias rondan el exceso y apelan a un estado de ignorancia suspendida entre la 'verdad' y la 'mentira' como apuesta fuerte contra el verosímil. Ambas indagan esos artefactos a que me referí, educación y justicia, precisamente dos dispositivos muy visibles en las tramas fundacionales de Bolívar, quien como Rousseau apelaba a una elevada idea de la educación y, como Montesquieu, a una elevada idea de la ley.

La esposa del Dr. Thorne (1988)[4] y La carujada (1990)[5] constituyen la saga (el uso es de Romero) que asedia el "culto a Bolívar". La primera es una novela erótica sobre vida y obra de Manuela Sáenz, la eterna amante de Simón Bolívar; la segunda, sobre vida y obra de Pedro Carujo, un implicado en el atentado "septembrino" contra Bolívar. Ambas instalan en las opciones temáticas y discursivas señaladas: son reescrituras de un panteón nacional aunque en sentido contrario al que Renan sugiriera y muchos historiadores propusieran ("Un pasado heroico, grandes hombres, gloria... es el capital social sobre el que se asienta una idea nacional"). Y se articulan sobre una combinatoria de escritura exacerbada y de elecciones referenciales que, siendo verificables, por gestos y circunstancias rondan el exceso y apelan a un estado de ignorancia suspendida entre la 'verdad' y la 'mentira' como apuesta fuerte contra el verosímil. Ambas indagan esos artefactos a que me referí, educación y justicia, precisamente dos dispositivos muy visibles en las tramas fundacionales de Bolívar, quien como Rousseau apelaba a una elevada idea de la educación y, como Montesquieu, a una elevada idea de la ley.

Mide el efecto de sus palabras como si dirigiérase a una multitud congregada más allá de las paredes del gran salón tapizadas con colgaduras de seda amarilla que llegan hasta el techo, más allá de los listones de terciopelo azul pálido que festonean los cuatro lados de la pieza, más allá de las ventanas recubiertas de cortinas color paja o del riquísimo enmaderado repleto de doradas molduras y bajorrelieves de personajes griegos. (La esposa... p. 11)

La escritura de Bolívar, sostenida en principios de economía y concentración, progresiva y altamente regulada hacia el logro de la utilidad y la eficacia (dominio de los padres del utilitarismo y de los juristas nominalistas, de la economía de producción, la actividad laboriosa y el ahorro) es contrariada por la de Romero, del suplemento y la demasía hacia la retórica del exceso que señalo. El gasto se da por un regodeo en casi lo mismo, la aclaración, la repetición, la acumulación, la suspensión y la dilación, un erotismo de la palabra en tanto actividad lúdica y cuya finalidad está en sí misma o en el goce que produce (SARDUY, p. 181-182)

Romero conoce bien la escritura que contradice: hasta describe su diseño al mencionar las aspiraciones de Carujo el protagonista de la otra novela citada: "Se cuida de usar una prosa límpida, equilibrada, eufónica, bien construida. Su imaginación, a menudo tildada de calenturienta, está contenida... Supone todo un esfuerzo de intelecto llegar a conmover a tantos...". Estas particularidades se suman a la pasión por escribir de Bolívar, quien concentra en sí mismo la doble vertiente de la noción de letrado indicada para el contexto de nuestra colonización[6]: legitima intelectualmente la propia empresa, en este caso la emancipadora vinculada a su proyecto continentalista, y se hace cargo de lo político y administrativo. Su batería de escritos normativos revela la compulsión por proclamar, decretar, reglamentar o legislar, por armar un aparato legal que la sostenga, constituyéndose en órgano de control y de poder.[7] Había aprendido de sus maestros que las constituciones son e resultado de los factores reales de poder y que las leyes convierten el poder en poder jurídico. Decía Montesquieu "Es un pensamiento admirable de Platón el que las leyes se hacen para anunciar los mandatos de la razón...". Estamos en el terreno de La carujada y la referencia a Platón no es ingenua. Entre lo excesivo (La carujada a diferencia de La esposa del Dr. Thorne tiende además, al monumentalismo), se asedia en especial la noción de Justicia. Se la atraviesa como aparato para redimensionarla como problema central de la República (texto y proyecto de donde un Carujo defensor de la república como 
forma bebe) y más aún, inextricablemente hermanada a la política. Como se sabe, la tentativa de Platón (TOUCHARD, p. 36-44) se encamina a salvar la moral y la política, al reencuentro de las "leyes ideales" o condiciones inexorables de un régimen perfecto. La J usticia como eje de una república obligaría a desprenderse de la utilidad como interés o conveniencia personales, y la Política se mediría entonces en relación con esta idea que arrastra las de Bien, Belleza y Bondad. Se trata de la gran república imaginada de la cultura occidental donde lo justo, lo bueno, lo bello y lo legal concurren en distribución equilibrada: un núcleo fundamental de la utopía de la razón.

Es difícil desligarse de la enunciación. Romero era abogado, un hombre de Derecho (ars boni et aequi), sabía que éste es el discurso del Poder (como lo sabían nuestros letrados criollos) y se lo apropia para burlarse, volviendo a contradecir la voluntad bolivariana. Por eso apela al descubrimiento del abuso de la ley (otra vez la distorsión) centrando la controversia jurídica como montaje de ficciones que desplazan nociones de "certeza" o "verdad" y destacan el lenguaje en movimiento con fines persuasivos, lo que finalmente se impone. Como Fourier, es despiadado con la Constitución (la Ley suprema que el francés tildaba de "absurdo cómico"). Y se regodea en la ciencia jurídica clásica y moderna a través del incompetente abogado del Carujo condenado a muerte, vociferando en jerga o citando "de memoria" desde el Derecho de Gentes, el Código de Justiniano, el Digesto, el Código de las Siete Partidas y las Instituciones, pasando por las Decretales de Gregorio IX, las Reglas de Bonifacio o "las doctrinas modernas". Cómo olvidar desde aquí a Bolívar y su pulsión. Pero me interesa una marca que en La Carujada es generadora. Si en La esposa de Thorne se da carnadura al deseo (lo que siempre está cuando de poder se trata), una palabra que Bolívar limita por el uso de la razón ("deseo racional" dice en la "Carta de Jamaica" [8]), en La Carujada se da carnadura a su impactante autoconciencia del fracaso. "He arado en el mar", "Ud. puede considerar si un hombre que ha sacado de la revolución las anteriores conclusiones..., tendrá ganas de ahogarse nuevamente después de haber salido del vientre de la ballena...". [9] Son frases que resumen el fracaso con la contundencia que caracteriza la escritura de Bolívar. Y es el des-borde en Romero, quien en la brecha de Roa Bastos, se sirve de una palabra, de una marca para levantar un texto de más de 400 páginas (su Yo-e/ Supremo es un gesto de autofiguración de Francia en sus escritos, quien fija una nación moderna fundado en la Teología jurídica medieval). La moral del fracaso impregna toda La Carujada. Es de política, pero de mucho más que se habla. Pienso en la serie literaria y recuerdo palabras de otro narrador maestro. "Esta moral..., salvo algunas rarísimas excepciones - dijo J. J. Saer (p.48-49)-, es la moral de toda la literatura occidental genuinamente representativa... es la línea principal que Cervantes tiende hacia la imaginación moderna...".

La conciencia de los límites impuestos por la razón o la pulsión de equilibrio que los fundadores mostraban son en Romero, el punto de partida: la semántica se apropia del lugar de la sin-taxis (con-orden). Sus narrativas, si apelan a nuestra fundación revisando ideas, sumergen además en la escritura que la plasmara para transformar la propia en "el tremendo caldero de las brujas" desde su base material misma (cuerpo de inscripción del acontecer histórico a través de formas pasadas que se incrustan y hacen presentes, donde asoman placeres y terrores, muerte, miedo y heridas, lengua y habla, ley, justicia, poder y perdón, palabras repetidas por los teóricos cuando definen la nación). Quizás Romero imaginó así la utopía de Barthes, una sociedad donde lenguajes diferentes coexisten sin agresiones (la ocupación espacial de esta novela es un espectáculo desuniformizado en su montaje y revela la intención del énfasis, de la agitación -antiguas aspiraciones sarmientinas-, también la lectura como operación previa expuesta). Romero conoce el mecanismo entrópico (Roa, dije, fue uno de sus maestros), en tanto desorden (lo que perturba el código, cualquiera sea) y en tanto mayor posibilidad de la narración. El culto a Bolívar es el des(o)culto a Bolívar: la frase pretende jugar su juego sintetizando la apuesta a la inversión y a un único poder/gobierno, el de las palabras.

\section{Referências}

BAECHLER, Jean. "La universalidad de la Nación", Nación y Modernidad (Gauchet, Manent Rosanvallon Dir). Bs. As: Nueva Visión 1997: p. 9-28.

BATAILLE, Georges. El erotismo. España: Tusquets, 1992.

BOLIVAR, Simón. Doctrina del Libertador. Caracas: Biblioteca Ayacucho, 1979.

FOUCAULT, Michel. Historia de la sexualidad 1- La voluntad de saber. México: Siglo XXI, 1977.

MARINONE, Mónica. "El sexo es bueno para pensar"- Signos literarios 3 (enero junio 2006): p. 61-83.

MIGNOLO, Walter, "Literariedad y colonización: un caso de semiosis colonial”, SyC-Nro 2 (Bs As, 1994):p. 91-119.

RAMA, Ángel. La ciudad letrada.Hanover: Ediciones del Norte, 1984.

RENAN, Ernest. "What is a Nation"?, Nation and Narration (BHABHA, Homi Coord.) London and New York: Routledge, 1990: p.9-22

ROUSSEAU, Juan J. Emilio. México: Edit. Porrúa, 1999.

SARDUY, Severo. "El barroco y el neobarroco", América Latina en su literatura (FERNÁNDEZ MORENO, César Coord.) México: Siglo XXI, 1984: p.167-188.

SAER, Juan J. La narración-objeto. Bs. As: Planeta, 1999.

TOUCHARD, J ean. Historia de las Ideas políticas. Madrid: Tecnos, 1975.

Recebido em 16/09/2008. Aprovado em 28/10/2008.

\section{Resumos}

Title: "When Words (and excess) Rule" - About Denzil Romero

Author: Mónica Marinone

Abstract: Venezuelan Denzil Romero has re-written History from Literature, and he has done it from the position of irreverence. This paper focuses on La esposa del Dr. Thorne (1988) and La carujada (1990), two novels about Simón Bolívar's lover's life and Pedro Carujo's life, who attempted against Bolivar, respectively. From the consideration of EDUCATION and JUSTICE, I try to reconstruct an (imaginary) archive that I perceive in the background, by which Romero ridicules the discussion about those "ideas" in the French Revolutionary context, reabsorbed by the XIXth century Latin-American foundational writing, especially S.Bolivar's.

Keywords: literature, history, revolution, eroticism, Romero.

Tìtre: “Quand les mots (et l'excès) commandent": Sur Denzil Romero

Auteur: Mónica Marinone

Résumé: Le vénézuélien Denzil Romero réécrit l'Histoire à partir de la Littérature, situé dans l'irrévérence. Cet article développe quelques idées sur ses romans La esposa del Dr. Thorne (1988) et La Carujada (1990), sur la vie et l'œuvre de la maîtresse de Bolívar, respectivement. À propos de la considération des axes ÉDUCATION et JUSTICE, cet article fait la reconstruction d'un archive (imaginaire) par lequel Romero investit dans les débats entre des penseurs français de l'époque révolutionnaire, quelques sources primaires des écrits du XIXème siècle latino-américain, surtout ceux de S. Bolívar.

Mots-clés: littérature, histoire, révolution, érotisme, Romero.

Título: Cuando las palabras (y el exceso) mandan - Sobre Denzil Romero

Autor: Mónica Marinone

Resumen: El venezolano Denzil Romero ha reescrito la Historia desde la Literatura emplazado en la irreverencia. Este artículo desarrolla algunas ideas sobre sus novelas La esposa del Dr. Thorne (1988) y La Carujada (1990), sobre vida y obra de la amante de Simón Bolívar y de Pedro Carujo, uno de quienes atentaron contra la vida de Bolívar, respectivamente. Desde la consideración de los ejes EDUCACIÓN y JUSTICIA, reconstruyo un archivo (imaginario) a través del cual Romero asedia los debates entre pensadores franceses de la época revolucionaria, algunos, fuentes primarias de los escritos del s. XIX latinoamericano, especialmente los de S. Bolívar.

Palabras-clave: literatura, historia, revolución, erotismo, Romero. 
[1] La definición es de BATAILLE.

[2] ROMERO, Denzil. La esposa del Dr. Thorne. Barcelona: Tusquets, 1990 (4ta. Ed.). Las citas y paginación anotadas corresponden a esta edición.

[3] Manejo la edición de Caracas: Planeta. Las citas y paginación referida corresponden a la misma. La tragedia del Generalísimo (1983), Gran Tour (1988) y Para seguir el vagavagar (1994) son la trilogía de Romero sobre Francisco de Miranda. Todas las novelas mencionadas constituyen la gran saga sobre la empresa libertadora orientada a instaurar la república.

[4] ROMERO, Denzil. La esposa del Dr. Thorne. Barcelona: Tusquets, 1990 (4ta. Ed.). Las citas y paginación anotadas corresponden a esta edición.

[5] Manejo la edición de Caracas: Planeta. Las citas y paginación referida corresponden a la misma. La tragedia del Generalísimo (1983), Gran Tour (1988) y Para seguir el vagavagar (1994) son la trilogía de Romero sobre Francisco de Miranda. Todas las novelas mencionadas constituyen la gran saga sobre la empresa libertadora orientada a instaurar la república.

[6]Angel Rama desarrolla detenidamente esta cuestión (La ciudad letrada: cap.II). Asimismo Walter Mignolo (p.104,105 y 106)

[7] Véanse por ejemplo, "Decreto en favor de los indígenas ", "Decreto de creación de Juntas Provinciales de Agricultura y Comercio", "Proyecto: El Poder Moral", "Ley de repartición de Bienes Nacionales" "Decreto de Creación del Consejo de Estado", "Decreto sobre preservación de las aguas y conservación de los bosques", "Ley contra los defraudadores de la Renta de Tabaco" (Doctrina del Libertador: ps.140, 143, 127, 86, 88, 215, 25 respectivamente)

[8] La cita es "me atrevo aventurar algunas conjeturas...dictadas por un deseo racional". La expresión se articula para desactivar la palabra "adivinación" (cuya fuerza después supera el esfuerzo de Bolívar, dado que la carta ha sido denominada "profética") respecto de sus conjeturas sobre el desarrollo político futuro en los países de América.

[9] "Carta al Gral. Juan José Flores".

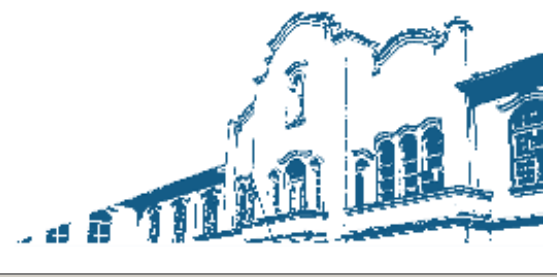

Copyright PPGCL/ Unisul 2006 @ (48) 3621-3369 - Desenvolvimento: Prof. Dr. Fábio J osé Rauen 